\title{
An Indoor Laboratory Simulation and Evaluation on the Aging Resistance of Polyether Polyurethane Concrete for Bridge Deck Pavement
}

OPEN ACCESS

Edited by:

Zhanping You,

Michigan Technological University,

United States

Reviewed by:

Haifang Wen,

Washington State University,

United States

Pedro Romero,

The University of Utah, United States

${ }^{*}$ Correspondence:

Shifa Xu

xu-sf@126.com

Specialty section:

This article was submitted to Structural Materials, a section of the journal

Frontiers in Materials

Received: 30 March 2020

Accepted: 29 June 2020

Published: 30 July 2020

Citation:

$X u$ S, Xu M, Zhang Y, Guo Y,

Peng G and Xu Y (2020) An Indoor Laboratory Simulation and Evaluation on the Aging Resistance of Polyether

Polyurethane Concrete for Bridge Deck Pavement. Front. Mater. 7:237.

doi: 10.3389/fmats.2020.00237

\begin{abstract}
Shifa $X u^{1,2 *}$, Meng $X u^{1,2,3}$, Yexing Zhang ${ }^{1}$, Yutao Guo ${ }^{1}$, Geng Peng ${ }^{1}$ and Ying $X u^{4}$
'School of Civil and Transportation Engineering, Beijing University of Civil Engineering and Architecture, Beijing, China, ${ }^{2}$ Beijing Advanced Innovation Center for Future Urban Design, Beijing University of Civil Engineering and Architecture, Beijing, China, ${ }^{3}$ Shandong Provincial Engineering Laboratory of Transportation Safety and Emergency Support Technology, Shandong Jiaotong University, Jinan, China, ${ }^{4}$ Beijing Urban Traffic Infrastructure Engineering Research Center, Beijing University of Civil Engineering and Architecture, Beijing, China
\end{abstract}

Polyether polyurethane concrete (PPC) is a new engineering material used for bridge deck pavement. In this article, the aging resistance performance of PPC for long-term service is evaluated. Based on the actual climate and environment conditions of bridge deck pavement, the indoor laboratory simulation considering various environmental factors was first proposed, and then the indoor accelerated aging tests of PPC were carried out. Finally, the Cantabro test, the low-temperature bending beam test, the rutting test, the splitting test under freeze-thaw cycle, and four-point bending fatigue test were conducted on the aged PPC specimens. The performances of anti-loose, resistance to permanent deformation, low temperature, water stability, and fatigue resistance were evaluated and compared with styreneic block copolymers (SBS) modified asphalt mixture (SBSM). Test results showed that PPC had good anti-aging performance, and the road performance of PPC after aging was still better than that of non-aging SBSM, which can be used for the long-term service as a bridge deck pavement material.

\section{Keywords: polyether polyurethane concrete, bridge deck pavement, road performance, anti-aging performance, simulation and evaluation}

\section{INTRODUCTION}

As an important part of bridge, the durability of bridge deck pavement is always a hot topic in the field of transportation infrastructure engineering (Wang and Liu, 2013; Sun and Chen, 2014; Geng et al., 2016; Qian et al., 2016; Hee et al., 2017; Zhang et al., 2018). At present, most of the bridge deck pavement materials are hot-mixed asphalt concretes. In many regions, there exists long-time high temperature in summer and fast cooling in winter. Asphalt materials are easy to deform at high temperature and crack at low temperature due to the strong temperature sensitivity. In addition, the phenomenon of vehicles that are overlimited and with overload has become more and more serious, leading to the shear failure of the pavement. If water continues to invade, it may further result in the loose failure of the structure (Guan et al., 2005; Yang, 2013). For these reasons, considering the remarkable progress in the traditional asphalt-based materials (Hou et al., 2017; Xu et al., 2018; Yang et al., 2020a,b), they still cannot achieve the long life of bridge deck pavement requirements.

Polyurethane polymer has good flexibility and elasticity suitable for service with long-term dynamic deflection. In addition, it has good mechanical properties, wide adhesion applicability, 
and low temperature sensitivity and can thus replace the asphalt materials to achieve the long-term service life of bridge deck pavement. Moreover, the polyether polyurethane concrete (PPC) can be mixed and constructed at room temperature, which significantly saves energy and reduces emission. Therefore, PPC has good engineering applicability as bridge deck pavement material.

In recent years, there have been many researches carrying out on the performance evaluation and application of polymer concrete all through the world. Li et al. (2019) carried out the experimental research on the key performances of polyurethane permeable mixture and analyzed the differences in mechanical properties and functional characteristics between polyurethane permeable mixture and porous asphalt mixture. Lu et al. (2019a,b) developed a sustainable permeable pavement material with recycled ceramic aggregate and biobased polyurethane adhesives. The mechanical properties, functional characteristics, and environmental performance of the material were evaluated and compared with the porous asphalt mixture. Lu et al. (2020) also analyzed the influences of saturation on the permeable pavement using the new polyurethane binder through finite element simulation. Lu et al. (2020) found that different graded PUPMs (polyurethane-bound pervious mixtures) have different failure characteristics, where the ductility can be increased by adjusting the aggregate gradation. Wang et al. (2014) carried out the experimental research on the strength and road performance of porous polyurethane macadam mixture and tested the influences of binder consumption and Macadam shape on its strength and road performance. Chen et al. (2018a) conducted studies on the anti-icing and de-icing performances of polymer concrete. They found that the icing time of polymer concrete was significantly longer than that of traditional asphalt concrete, and the work required to destroy the ice layer on its surface was only $50 \%$ of that of asphalt concrete. Chen et al. (2018b) discussed the durability and functional performance of porous polyurethane mixture (PPM) instead of open-graded friction course (OGFC) in porous pavement. Wang et al. (2017b) conducted studies on the effects of various composition factors on the easy loosening of poroelastic road surface (PERS). Wang et al. (2017a) explored the possibility of using PERS on urban roads in cold areas. Gao et al. (2019) evaluate the comprehensive properties of polyurethane rubber particle mixture (PRPM) at high temperature, antiaging, and skid resistance and showed PRPM had superior comprehensive performance, but slightly lower skid resistance. Biligiri et al. (2013) conducted studies on the basic material (stiffness) characteristics of PERS related to pavement design. Cong et al. (2018) conducted studies on the PPMs and asphaltbonded porous mixtures (APMs), which showed that the PPM obtained three times' higher stability and over one order of magnitude greater fatigue life than APM. Polyurethane mixtures are mainly used in the following fields: OGFC, PPM, PERS, and self-stressing deicing mixture (Cong et al., 2019).

Wang et al. (2018) developed the PPC as the bridge deck pavement material, evaluated its road performance, and proposed that the residual splitting strength under freeze-thaw cycles should be used as the water stability index of PPC. They found that the dynamic stability and low-temperature bending tensile strain of PPC were nearly 10 times higher than asphalt mixture, and the fatigue life was more than 1 million times. The splitting strength under freeze-thaw cycle is similar to that of SMA asphalt mixture without freeze-thaw cycle. Based on the above findings, PPC has excellent road performance, but as a polymer material, its molecular chain may have degradation reaction affected by many environmental factors including air, temperature, light, water, and so on. Besides, polyurethane binder is a thermosetting material and does not have the self-healing performance as asphalt material. Therefore, in engineering practice, the properties of polyurethane binder will be irreversibly affected by aging under the severe environmental conditions, resulting in the decrease of the cohesive force between the aggregate and polyether polyurethane binder, and finally affect the physical and mechanical properties of PPC. Although some scholars have conducted some research on polyurethane mixtures, the anti-aging property of polyurethane concrete used as a bridge deck pavement material is still one of the most significant problems for the pavement industry.

In this study, the indoor laboratory accelerated aging tests were used to simulate the severe environmental conditions of PPC during the regular service life. The aging resistances of PPC were evaluated and compared with the non-aging styreneic block copolymers (SBS) modified asphalt mixture (SBSM), based on a number of road performance tests, which will provide the theoretical and experimental basis for future application of PPC as a bridge deck pavement material.

\section{RAW MATERIALS AND TEST METHODS}

\section{Raw Materials \\ Polyurethane Binder}

The self-developed single-component polyether polyurethane, which is a black thermosetting material, can be mixed at room temperature. It has good adhesion performance with aggregate after curing, and the test results are shown in Table 1. Polyurethane binder for pavement is mainly formed by polymerization addition of polyether polyol and polyisocyanate. In the material design, the multifunctional oxazolidine curing agent is used, which can preferentially react with water to generate amino $\left(-\mathrm{NH}_{2}\right)$, hydroxy $(-\mathrm{OH})$, and then cross-link with isocyanate (-NCO) to form elastomer with network structure that can effectively reduce the generation of bubbles and improve the strength of elastomer.

\section{Asphalt}

In this study, SBSM is also tested for comparison, where SBSmodified asphalt with penetration $\left(25^{\circ} \mathrm{C}, 0.1 \mathrm{~mm}\right)$ of 66 , ductility of $37 \mathrm{~cm}$ at $5^{\circ} \mathrm{C}$, softening point of $73^{\circ} \mathrm{C}$, and elastic recovery rate of $95 \%$ at $25^{\circ} \mathrm{C}$ is used.

\section{Mineral Aggregate}

The aggregate was basalt, and the filler was limestone mineral powder. All the technical indexes met the requirements of Technical Specifications for Construction of Highway Asphalt Pavement in China (JTG F40-2004, 2004), as shown in Table 2. 
TABLE 1 | Technical properties of polyurethane.

\begin{tabular}{|c|c|c|c|c|}
\hline Test & Unit & Technical quality requirements & Result & Test method \\
\hline Density & $\mathrm{g} / \mathrm{cm}^{3}$ & - & 1.1 & GB/T. 4472-2011, 2011 \\
\hline Tensile strength $\left(25^{\circ} \mathrm{C}\right)$ & $\mathrm{MPa}$ & $\geq 2.0$ & 2.5 & GB/T. 16777-2008, 2008 \\
\hline Elongation at break $\left(25^{\circ} \mathrm{C}\right)$ & $\%$ & $\geq 150$ & 155 & \\
\hline Surface dry time $\left(25^{\circ} \mathrm{C}\right)$ & $\mathrm{h}$ & $0.5-4$ & 1.5 & \\
\hline Inside dry time $\left(25^{\circ} \mathrm{C}\right)$ & $\mathrm{h}$ & 8-25 & 14 & \\
\hline Water impermeability (0.3 MPa, 24 h) & - & Impermeable & Impermeable & \\
\hline Water absorption rate & $\%$ & $\leq 4$ & 2 & GB/T. 1034-2008, 2008 \\
\hline Kinematic viscosity $\left(25^{\circ} \mathrm{C}\right)$ & mPa.s & $\leq 3,000$ & 2,550 & JTG E20/T 0619 \\
\hline
\end{tabular}

TABLE 2 | Technical properties of aggregate.

\begin{tabular}{llcc}
\hline Type & Technical properties & Aggregate A & Aggregate B \\
\hline Coarse aggregate & Apparent density $\left(\mathrm{g} / \mathrm{cm}^{3}\right)$ & 2.913 & 2.921 \\
& Bulk density $\left(\mathrm{g} / \mathrm{cm}^{3}\right)$ & 2.876 & 2.882 \\
& Water absorption $(\%)$ & 0.44 & 0.46 \\
& Crushing value $(\%)$ & 9.5 & 10.4 \\
& Los Angeles abrasion & 10.5 & 11.9 \\
& value $(\%)$ & & 3.3 \\
& Content of needle and & 4.6 & 0.6 \\
& flake $(\%)$ & & \\
Fine aggregate & Apparent density $\left(\mathrm{g} / \mathrm{cm}^{3}\right)$ & & 2.725 \\
Mineral powder & Apparent density $\left(\mathrm{g} / \mathrm{cm}^{3}\right)$ & & 2.718 \\
\hline
\end{tabular}

\section{Preparation of Mixture and Mix Ratio}

Polyether polyurethane concrete (hereinafter referred to as PPC13) and SBSM (hereinafter referred to as SBSM-13) with the maximum nominal particle size of $13 \mathrm{~mm}$ were selected for the comparative tests, and the gradation of mineral aggregate is shown in Table 3.

The Marshall design method was used for the mixture design. The material properties of PPC and asphalt mixture are different, and the requirements of stability and voidage are also different. Previous research (Shi, 2018) shows that the voidage of PPC can meet the requirements within the range of $2.0-3.5 \%$. According to the test results, the binder-aggregate ratio of PPC-13 and SBSM-13 is 7 and $5.4 \%$, respectively.

The preparation of PPC specimen was as follows: after the aggregate was evenly mixed according to the designed gradation, it was added into the mixing pot for dry mixing at room temperature for $90 \mathrm{~s}$. Then the polyurethane binder was evenly mixed with the aggregate for $90 \mathrm{~s}$. Finally, the mineral powder was added and mixed for $90 \mathrm{~s}$, where the PPC specimen was formed after curing at room temperature for a certain time.

\section{TEST DESIGN}

\section{Indoor Laboratory Simulation Aging Test}

At present, there are very few studies on the aging resistance of PPC as a bridge deck pavement material in the actual service environment, and there is no official specification for reference. In this study, to reflect the effects of the actual service environmental conditions on bridge deck pavement, the indoor laboratory simulation test was designed. The methods of photothermal coupling aging and thermo-oxidative aging were applied on the PPC specimens; based on a number of road performance tests after aging, the effects of temperature and ultraviolet (UV) light on the road performance of PPC were studied. The non-aging SBSM was used for comparison; since the performance of aged PPC is better than the non-aging SBSM, the performance of aged PPC is better than that of aged SBSM. Moreover, sometimes the aged SBSM specimens are fragile and too easy to fail; in this case, the non-aging SBSM specimen was used for testing.

\section{Thermo-Oxidative Aging Simulation}

At high temperature in summer, polyurethane binder will have oxidation reaction, that is, thermo-oxidative aging. Polyether polyurethane concrete is mixed at room temperature, so its thermo-oxidative aging generally occurs after paving. In China, the temperature of bridge deck in summer can reach approximately $60^{\circ} \mathrm{C}$. In order to simulate the thermo-oxidative aging of PPC under high temperature in summer, PPC specimens were placed in the ventilation oven at $60^{\circ} \mathrm{C}$ for $1,2,3,4,5$, and 6 weeks, respectively, to simulate the thermo-oxidative aging in actual environment conditions.

Relevant research (Luo et al., 1999; Shen et al., 2014; Ionita et al., 2020) shows that the thermo-oxidative aging of polyurethane will increase with the increase of temperature. In order to improve the aging rate and to realize the thermooxidative aging effect for long-term service of bridge deck pavement in a short time, $90^{\circ} \mathrm{C}$ was selected as the accelerated aging condition, where the effect of temperature difference on the aging resistance of PPC was also compared.

\section{Photothermal Coupling Aging Simulation}

The photochemical reaction of polyurethane binder, such as molecular chain breaking or group falling off, will occur under sunlight irradiation, known as photoaging. The UV radiation ability is the strongest in sunlight, which may result in significant damage to polyurethane binder. Therefore, to simulate the most critical state, the self-developed UV aging weatherometer with irradiance of $160 \mathrm{~W} \cdot \mathrm{m}^{-2}$ and test temperature of $60^{\circ} \mathrm{C}$ was used to irradiate the PPC specimens for 1, 2, 3, 4, 5, and 6 weeks, respectively, as shown in Figure 1. 
TABLE 3 | Gradation of aggregate.

\begin{tabular}{|c|c|c|c|c|c|c|c|c|c|c|}
\hline \multirow[t]{2}{*}{ Gradation type } & \multicolumn{10}{|c|}{ Mass percentage passing the following sieve $(\mathrm{mm})(\%)$} \\
\hline & 0.075 & 0.15 & 0.3 & 0.6 & 1.18 & 2.36 & 4.75 & 9.5 & 13.2 & 16 \\
\hline PPC-13 & 5.6 & 11.7 & 13.9 & 16.6 & 22.4 & 31.8 & 50.4 & 76.7 & 95.9 & 100 \\
\hline SBSM-13 & 5.6 & 11.7 & 13.9 & 16.6 & 22.4 & 31.8 & 50.4 & 76.7 & 95.9 & 100 \\
\hline
\end{tabular}

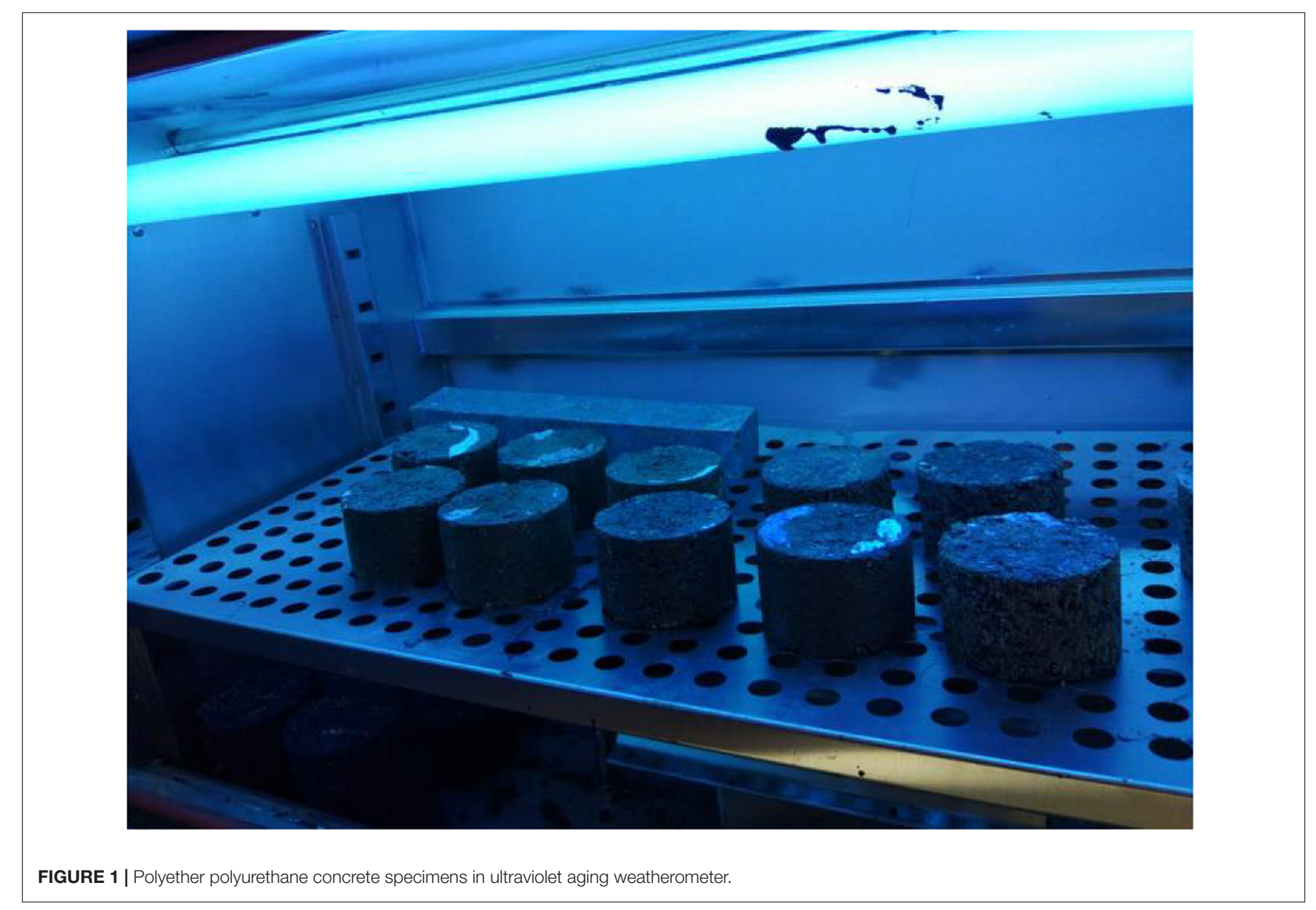

Based on the meteorological data, the annual UV radiation amount in Beijing is $294.8\left(\mathrm{MJ} \cdot \mathrm{m}^{-2}\right)$. According to the equivalent conversion between the indoor and outdoor radiation energy, the UV irradiation using weatherometer for 1 week is equivalent to that of the bridge deck in the natural environment for 120 days.

\section{Road Performance Test After Aging}

In this study, three test conditions of $60^{\circ} \mathrm{C}$ aging, $90^{\circ} \mathrm{C}$ aging, and photothermal coupling aging were applied on the PPC specimens and the non-aging SBSM specimens, and then a number of road performance tests were carried out for comparison.

\section{Anti-loose performance}

Cantabro durability test can be used to evaluate the phenomenon of aggregate falling off under traffic load due to insufficient cohesion. According to the Standard Test Methods of Bitumen and Bituminous Mixtures for Highway Engineering in China (JTG E20-2011, 2011), Cantabro test was carried out. After aging, PPC specimens were immersed in $20^{\circ} \mathrm{C}$ water bath for $20 \mathrm{~h}$. The comparison group was non-aging SBSM.

It is found that the mass loss of PPC is kept within 3\% under various environmental conditions in the initial test, indicating that PPC has good anti-loose performance, but at the same time, the mass loss cannot effectively quantify the relationship between anti-loose performance and aging conditions of PPC. In this study, the splitting strength loss before and after the test is used as the evaluation index of anti-loose performance. The splitting strength loss is calculated according to the following Eq. (1)

$$
\nabla P=\frac{P_{0}-P_{1}}{P_{0}} \times 100 \%
$$




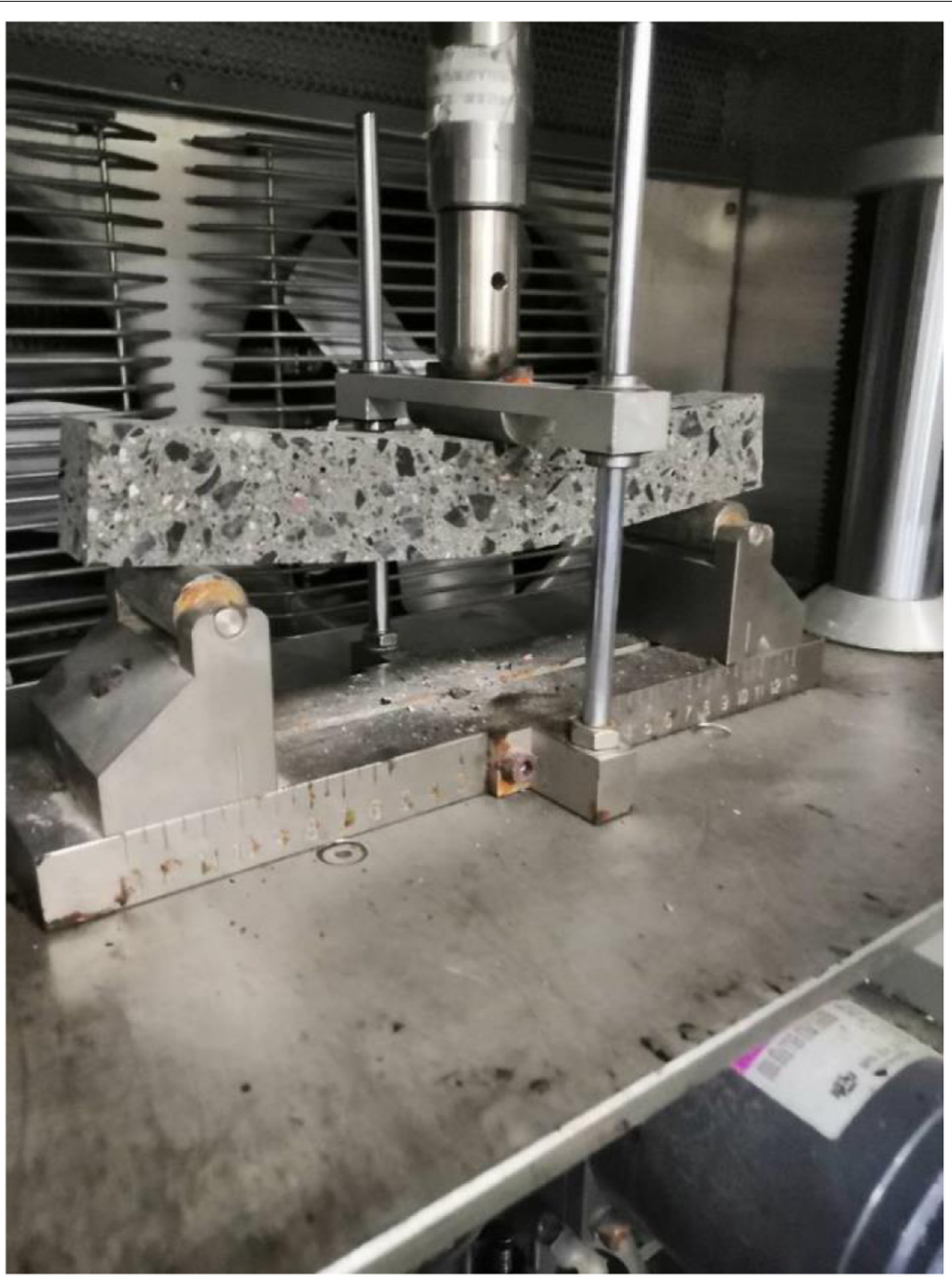

FIGURE 2 | Low-temperature cracking test on the UTM-25 servo hydraulic multifunctional material test system.

where $\nabla P$ is the splitting strength loss (\%), $P_{0}$ is the splitting strength before test $(\mathrm{MPa})$, and $P_{1}$ is the splitting strength after test (MPa).

\section{Low-temperature crack resistance}

Low-temperature cracking is a common pavement distress in cold regions. Polyether polyurethane concrete, as a bridge deck pavement material, is required to maintain good low-temperature crack resistance for long-term service. In this study, referring to the Standard Test Methods of Bitumen and Bituminous Mixtures for Highway Engineering in China (JTG E20-2011, 2011), the low-temperature bending beam test was conducted. The test specimens were formed by wheel milling and cut into the small beam with the size of $250 \mathrm{~mm} \times 30 \mathrm{~mm} \times 35 \mathrm{~mm}$. The lowtemperature performance of the small beam at different aging stages was tested at $-10^{\circ} \mathrm{C}$ using the UTM- 25 servo hydraulic multifunctional material test system, as shown in Figure 2.

\section{Resistance to permanent deformation}

In this study, according to the Standard Test Methods of Bitumen and Bituminous Mixtures for Highway Engineering in China (JTG E20-2011, 2011), the rutting test of mixture was carried out to evaluate the PPC resistance to permanent deformation by measuring the dynamic stability of PPC after aging. In the test, the wheel-rolling method was used to form a $300-\mathrm{mm} \times 300-$ $\mathrm{mm} \times 50-\mathrm{mm}$ rutting test specimen. During the test, the tire pressure was $0.7 \mathrm{MPa}$, the test temperature was $60^{\circ} \mathrm{C}$, and the rolling speed was 42 times/min.

\section{Water stability test}

When the bridge deck pavement is in regular service, water vapor in the environment will lead to the degradation and swelling of polyurethane binder, and the dynamic water pressure and scouring force under the load will lead to the decrease of the binding force between the binder and aggregate, which will 

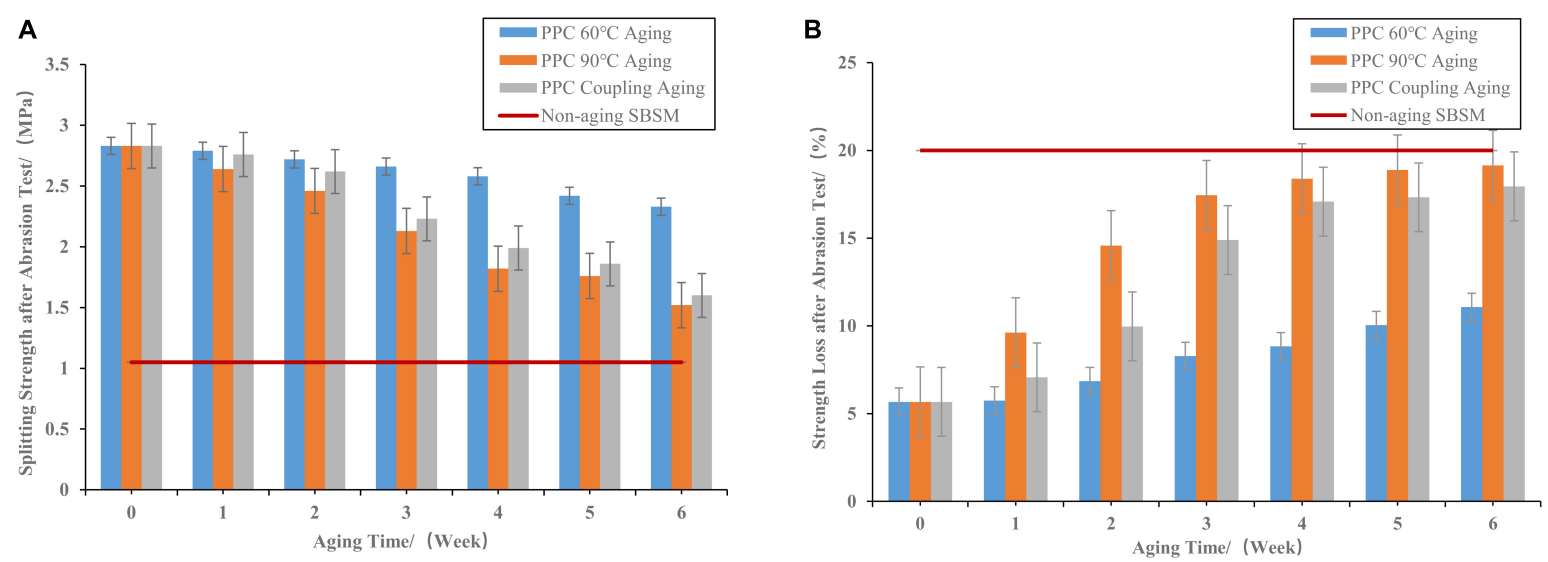

FIGURE 3 | Anti-loose performance of PPC and SBSM. (A) Splitting strength after abrasion test. (B) Strength loss after abrasion test.

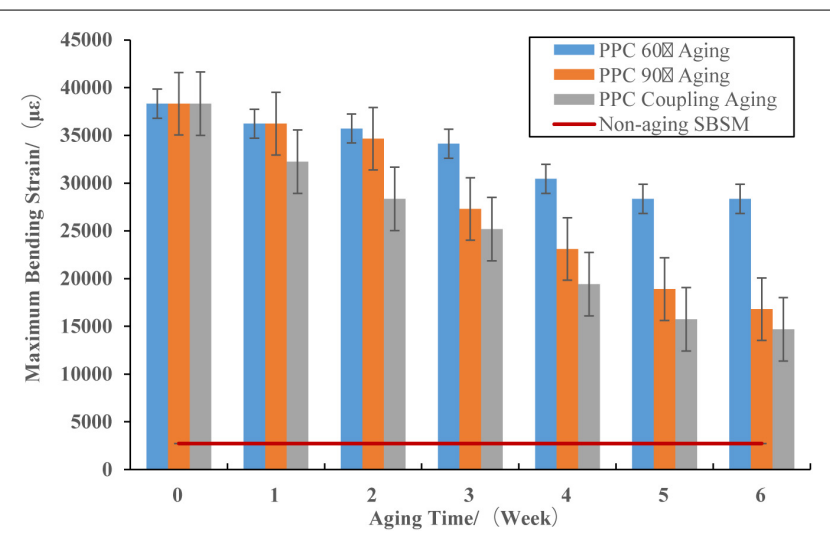

FIGURE 4 | Low-temperature crack resistance of PPC and SBSM.

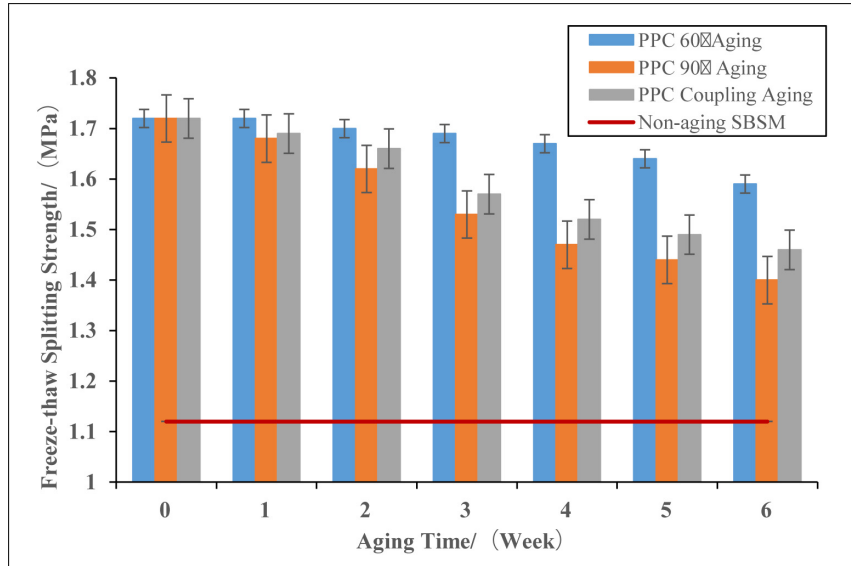

FIGURE 5 | Splitting strength under freezing-thawing cycle after aging .

eventually cause the pavement damage. Especially in summer and winter, the temperature change is significant, and the precipitation is large, and the water temperature in the deck pavement changes frequently. In order to simulate the water temperature change of PPC in the actual service environment, the aged PPC specimens were tested under freeze-thaw cycle. According to the Standard Test Methods of Bitumen and Bituminous Mixtures for Highway Engineering in China (JTG E20-2011, 2011), the freeze-thaw split test method was adopted. After the test sample was saturated with water in vacuum for $15 \mathrm{~min}$, it was placed in the environment of $-18^{\circ} \mathrm{C}$ for $16 \mathrm{~h}$, and then the test sample was treated in constant temperature water bath of $60^{\circ} \mathrm{C}$ for $24 \mathrm{~h}$ and finally in constant-temperature water bath of $25^{\circ} \mathrm{C}$ for $2 \mathrm{~h}$.

\section{Fatigue resistance test}

In order to evaluate the fatigue resistance of PPC after aging, the four-point bending fatigue test was carried out on the UTM-25 hydraulic servo control system, where loading strain 1,200 $\mu \varepsilon$ was selected to reflect the impact of heavy load traffic. The loading mode was sine wave, the loading frequency was $10 \mathrm{~Hz}$, the test temperature was $15^{\circ} \mathrm{C}$, and the test specimen was 380 $\mathrm{mm} \times 63.5-\mathrm{mm} \times 50-\mathrm{mm}$ beam.

It was found that the fatigue life of PPC was more than 1 million times under various environmental conditions, indicating that PPC had good fatigue resistance performance. Meanwhile, the fatigue life cannot effectively quantify the relationship between PPC fatigue resistance and the aging conditions. Some studies (Ni and Yin, 2005) have shown that the initial stiffness modulus of the material can be used to characterize its ability to bear the repeated loads. Under the same strain conditions, the smaller the initial stiffness modulus of the concrete is, the stronger its ability to bear the repeated loads. In this study, the stiffness modulus of the test specimens after the 50 th cycle of loading at the strain level of $1,200 \mu \varepsilon$ was set as the initial stiffness modulus. The initial stiffness modulus of PPC and SBSM under different environmental conditions was tested, and the change rate of the initial stiffness modulus was used as the evaluation index of fatigue resistance. The change rate of the initial stiffness modulus is calculated according to the following Eq. (2):

$$
\nabla S=\frac{S_{0}-S_{1}}{S_{0}} \times 100 \%
$$




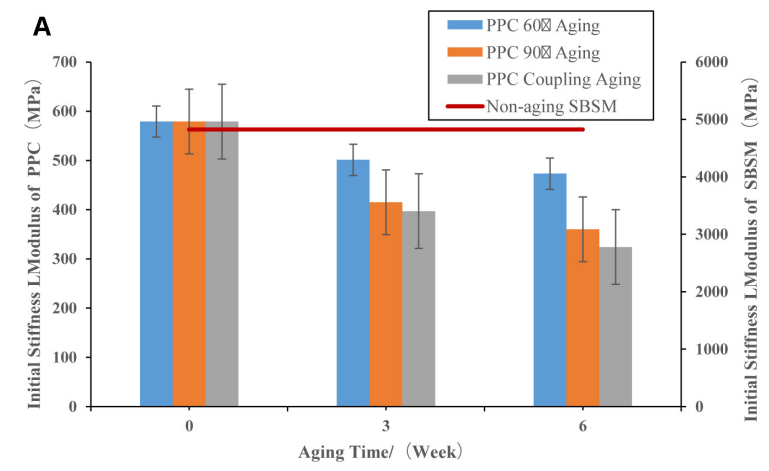

Initial stiffness modulus after aging

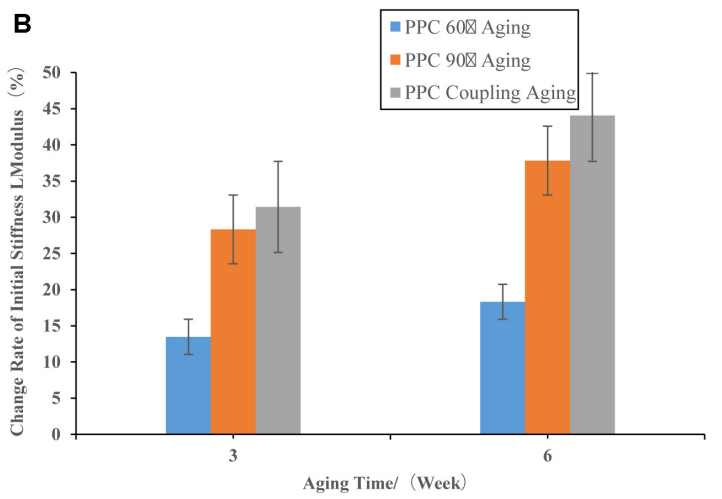

Change rate of initial stiffness modulus after aging

FIGURE 6 | Comparison of fatigue resistance after aging. (A) Initial stiffness modulus after aging. (B) Change rate of initial stiffness modulus after aging.

where $\nabla S$ is the loss rate of initial stiffness modulus (\%), $S_{0}$ is the initial stiffness modulus before aging $(\mathrm{MPa})$, and $\mathrm{S}_{1}$ is the initial stiffness modulus after aging $(\mathrm{MPa})$.

\section{TEST RESULTS AND ANALYSIS}

\section{Anti-loose Performance}

Figure 3 compared the anti-loose performance of aged PPC and non-aging SBSM, and error bars were applied to illustrate the deviation of testing results of PPC under different aging conditions. The following can be found:

1. After 6 weeks of aging, the splitting strength loss of PPC at $90^{\circ} \mathrm{C}$ was about 1.7 times of that at $60^{\circ} \mathrm{C}$, indicating that the thermo-oxidative aging effect at $90^{\circ} \mathrm{C}$ was more significant.

2. After 6 weeks of aging, the splitting strength loss of PPC under the condition of photothermal coupling aging (17.95\%) was significantly greater than that of $60^{\circ} \mathrm{C}$ (11.07\%), indicating that UV light and heat exhibit significant coupling effect, which was more significant than the effect of single thermo-oxidative aging on the anti-loose performance of PPC, and thermo-oxidative aging at $60^{\circ} \mathrm{C}$ had a greater impact on anti-loose performance of PPC than that of UV aging.

3. For all the three aging conditions, the splitting strength of PPC decreased. After 6 weeks of aging, the splitting strength of PPC under three aging conditions was 2.33, 1.52 , and $1.60 \mathrm{MPa}$, which were still significantly higher than that of the non-aging SBSM (1.05 MPa). The loss rate of strength under three conditions was 11.07, 19.15, and $17.95 \%$, respectively, and was also lower than that of the non-aging SBSM (20\%), which showed that PPC had better anti-loose performance than the SBSM for long-term service.

\section{Low-Temperature Cracking Resistance}

Figure 4 compares the maximum bending tensile strain of aged PPC and non-aging SBSM, and error bars were applied to illustrate the deviation of maximum bending tensile strain of PPC under different aging conditions. The following can be found:

1. After 6 weeks of aging, the maximum bending strain decreasing rate of $90^{\circ} \mathrm{C}$ thermo-oxidative aging (56\%) was about 2.2 times of $60^{\circ} \mathrm{C}(26 \%)$, indicating that the thermo-oxidative aging effect at $90^{\circ} \mathrm{C}$ was more significant, which was basically consistent with the previous analysis.

2. The decreasing rate of the maximum bending strain under photothermal coupling aging (61\%) was significantly higher than that under $60^{\circ} \mathrm{C}(26 \%)$. Therefore, it was concluded that UV light and heat exhibit significant coupling effect, which was more significant than the effect of single thermo-oxidative aging on the low-temperature performance of PPC, and UV light had a greater impact on low-temperature performance of PPC than the high temperature of the road surface during the service life. The main reasons are as follows: first, some of the molecular chains in polyurethane undergo oxidation reaction at high temperature, and some chemical bonds break, resulting in the decrease of material performance. And the higher the temperature is, the more violent the reaction will be. Second, UV light can irradiate into the internal microstructure of the material, and long-term irradiation causes large amounts of the chemical bonds break in polyurethane, and the free radicals gradually solidify, resulting in the increasing in the material rigidity and decreasing in flexibility at low temperature. The bending and tensile properties thus decrease.

3. For all the three aging conditions, the maximum bending tensile strain of PPC decreased. However, after 6 weeks of aging, the maximum bending tensile strain of PPC was $28,350,16,835$, and $14,721 \mu \varepsilon$, which were still better than that of non-aging SBSM $(2,723 \mu \varepsilon)$, which showed that PPC had better low-temperature crack resistance performance than SBSM for long-term service. 


\section{Resistance to Permanent Deformation}

The dynamic stability of non-aging PPC was 46,835 (s/mm); after 6 weeks of aging, the dynamic stability values of PPC under three aging conditions were 47,598, 48,125, and 49,661 s/mm. For the non-aging SBSM, it was $6,640(\mathrm{~s} / \mathrm{mm})$. It can be found that, after aging, the dynamic stability of PPC did not change significantly and was significantly higher than that of SBSM. Therefore, PPC has better resistance to permanent deformation than SBSM. The reason is that the deformation of PPC under high temperature and traffic load will gradually recover after unloading.

\section{Water Stability}

Figure 5 compares the freeze-thaw splitting strength of PPC under three aging conditions, and error bars were applied to illustrate the deviation of freeze-thaw splitting strength of PPC under different aging conditions. The following can be found:

1. After 6 weeks of aging, the decreasing rate of freeze-thaw splitting strength at $90^{\circ} \mathrm{C}$ thermo-oxidative aging (18.6\%) was about 2.4 times of that at $60^{\circ} \mathrm{C}(7.6 \%)$, which was similar to the previous conclusion.

2. By comparing the freeze-thaw splitting strength of PPC under $60^{\circ} \mathrm{C}$ and photothermal coupling aging conditions, it can be found that the freeze-thaw splitting strength decreasing rate of PPC under photothermal coupling aging $(15.1 \%)$ was about 2 times of that under $60^{\circ} \mathrm{C}$ (7.6\%). It showed that in the actual service environment of bridge deck pavement, UV light and heat exhibit significant coupling effect, which was more significant than the effect of single thermo-oxidative aging on the water stability of PPC.

3. The freeze-thaw splitting strength of PPC decreased under three aging conditions. However, after 6 weeks of aging, the freeze-thaw splitting strength of PPC under three aging conditions was 1.59, 1.40, and $1.46 \mathrm{MPa}$, respectively, which were significantly higher than that of non-aging SBSM (1.12 MPa). Results show that the water stability of PPC is better than that of SBSM.

\section{Fatigue Resistance Performance}

Figures 6A,B compare the fatigue resistance of aged PPC and non-aging SBSM, and error bars were applied to illustrate the deviation of testing results of PPC under different aging conditions. The following are found:

1. After 6 weeks of aging, the change rate of initial stiffness modulus of PPC at $90^{\circ} \mathrm{C}(37.8 \%)$ was about 2.1 times of that at $60^{\circ} \mathrm{C}(18.3 \%)$, indicating that the aging effect at $90^{\circ} \mathrm{C}$ was more significant.

2. Under the condition of photothermal coupling aging, the change rate of initial stiffness modulus of PPC (44.0\%) was 2.4 times of that at $60^{\circ} \mathrm{C}$, which indicated that UV light had a greater impact on the fatigue resistance of PPC in the actual service environment of bridge deck pavement.

3. The initial stiffness modulus of PPC decreased under three aging conditions. After 6 weeks of aging, the initial stiffness moduli of PPC under three aging conditions were 473,360 , and $324 \mathrm{MPa}$, which were significantly lower than the non-aging SBSM $(4,823 \mathrm{MPa})$. It showed that the ability of PPC to bear repeated load under constant loading was better than that of SBSM, and PPC had good fatigue resistance. The reason is that, when polyurethane binder reacts with thermo-oxidative aging and photothermal coupling aging, the chemical bond with small bond energy breaks, the molecular weight decreases, and cracks gradually appear, which leads to the decrease of stiffness modulus.

\section{SUMMARIES AND CONCLUSION}

As a new pavement material, the performance and material composition of PPC are significantly different from the traditional asphalt mixture. In this article, indoor laboratory tests were used to simulate the aging of PPC in the long-term service by photothermal coupling aging and thermo-oxidative aging. Compared with the non-aging SBSM, the properties of PPC after aging are systematically analyzed and evaluated. The main conclusions are as follows:

1. The indoor simulation method of the outdoor environment effects on PPC was proposed. The ventilation oven was used to simulate the thermooxidative aging under the high temperature of the road surface at $60 ; 90^{\circ} \mathrm{C}$ was used as the indoor thermo-oxidative accelerated aging condition. The selfdeveloped UV weatherometer was used to simulate the photothermal coupling aging of PPC during service with irradiation of $160 \mathrm{~W} \cdot \mathrm{m}^{-2}$ and test temperature of $60^{\circ} \mathrm{C}$.

2. According to the results of Cantabro test, after 6 weeks of aging, the splitting strength loss of $\mathrm{PPC}$ at $90^{\circ} \mathrm{C}$ was about 1.7 times of that at $60^{\circ} \mathrm{C}$. Ultraviolet light and heat exhibit significant coupling effect that had a greater impact on the anti-loose performance of PPC than the single thermooxidative aging at $60^{\circ} \mathrm{C}$. The splitting strength of PPC under three aging conditions was significantly higher than that of the non-aging SBSM, and the loss rate of strength was also lower than that of the non-aging SBSM, which indicated that PPC had better anti-loose performance than SBSM for long-term service.

3. According to the results of low-temperature bending beam test, aging rate of $90^{\circ} \mathrm{C}$ was approximately 2.2 times of $60^{\circ} \mathrm{C}$. The UV light had a greater impact on the lowtemperature performance of PPC than that of $60^{\circ} \mathrm{C}$. After 6 weeks of aging, the maximum bending tensile strain of PPC was still better than that of the non-aging SBSM, which showed that PPC had better low-temperature crack resistance than SBSM for the long-term service.

4. According to the rutting test results, after aging, the dynamic stability of PPC did not change significantly and was significantly higher than that of the non-aging SBSM, which indicated that PPC had stronger ability of permanent deformation resistance than that of SBSM. 
5. According to the results of freeze-thaw splitting test, the aging rate at $90^{\circ} \mathrm{C}$ was approximately 2.4 times of that at $60^{\circ} \mathrm{C}$. Ultraviolet light and heat exhibit significant coupling effect that had a greater impact on the water stability of PPC than the single thermo-oxidative aging at $60^{\circ} \mathrm{C}$. After 6 weeks of aging, the freeze-thaw splitting strength of PPC under three aging conditions was significantly higher than that of non-aging SBSM, indicating that the water stability of PPC was better than that of SBSM.

6. According to the results of four-point bending fatigue test, the fatigue life of PPC under various test environments was more than 1 million times under $1,200-\mu \varepsilon$ strain level. The change rate of initial stiffness modulus of PPC at $90^{\circ} \mathrm{C}$ was about 2.1 times of that at $60^{\circ} \mathrm{C}$. The UV light had a greater impact on the fatigue resistance of $\mathrm{PPC}$ than that of $60^{\circ} \mathrm{C}$. After 6 weeks of aging, the initial stiffness modulus of PPC under three aging conditions was significantly lower than the non-aging SBSM, which indicated that PPC had better fatigue resistance.

7. The research results of this study provide a reference for the future engineering application of polyether polyurethane as a bridge deck pavement material. However, because of the lack of field engineering project application, the reliability of indoor simulation method still needs to be verified and optimized in future studies, and more studies on the interaction mechanism between

\section{REFERENCES}

Biligiri, K. P., Kalman, B., and Samuelsson, A. (2013). Understanding the fundamental material properties of low-noise poroelastic road surfaces. Intern. J. Pavement Eng. 14, 12-23. doi: 10.1080/10298436.2011.60 8798

Chen, J., Ma, X., Wang, H., Xie, P. Y., and Huang, W. (2018a). Experimental study on anti-icing and deicing performance of polyurethane concrete as road surface layer. Construct. Build. Mater. 161, 598-605. doi: 10.1016/j.conbuildmat.2017. 11.170

Chen, J., Yin, X., Wang, H., and Ding, Y. (2018b). Evaluation of durability and functional performance of porous polyurethane mixture in porous pavement. J. Clean. Product. 188, 12-19. doi: 10.1016/j.jclepro.2018.03.297

Cong, L., Wang, T., Tan, L., Yuan, J., and Shi, J. (2018). Laboratory evaluation on performance of porous polyurethane mixtures and OGFC. Construct. Build. Mater. 169, 436-442. doi: 10.1016/j.conbuildmat.2018.02.145

Cong, L., Yang, F., Guo, G. H., Ren, M., and Tan, L. (2019). The use of polyurethane for asphalt pavement engineering applications: a state-of-the-art review. Construct. Build. Mater. 225, 1012-1025. doi: 10.1016/j.conbuildmat. 2019.07.213

Gao, J. F., Wang, H. N., Chen, J. K., Meng, X. W., and You, Z. (2019). Laboratory evaluation on comprehensive performance of polyurethane rubber particle mixture. Construct. Build. Mater. 224, 29-39. doi: 10.1016/j.conbuildmat.2019. 07.044

GB/T. 1034-2008 (2008). Plastic-Determination of Water Absorption. Beijing: General Administration of Quality Supervision, Inspection and Quarantine.

GB/T. 16777-2008 (2008). The Methods for Building Waterproofing Coating. Beijing: General Administration of Quality Supervision, Inspection and Quarantine. polyurethane and ore interface will be conducted to relate the chemophysical changes to the observed mechanical changes.

\section{DATA AVAILABILITY STATEMENT}

The raw data supporting the conclusions of this article will be made available by the authors, without undue reservation.

\section{AUTHOR CONTRIBUTIONS}

SX and MX: conceptualization and writing-original draft preparation. SX, MX, and YZ: methodology. MX, YG, GP, and YX: investigation. YZ, YG, and GP: the data curation. SX, MX, and YX: writing-review and editing. YX, YG, and GP: visualization. SX: supervision, project administration and funding acquisition. All authors contributed to the article and approved the submitted version.

\section{FUNDING}

This article was supported by the National Natural Science Foundation of China (Nos. 51978034 and 51678028) and the Beijing University of Civil Engineering and Architecture's Beijing Advanced Innovation Center for Future Urban Design's major scientific and technological project "Technology and Application of Disaster Reduction and Emission Reduction for Major Road Projects in the Capital” (No. X18159).

GB/T. 4472-2011 (2011). Determination of Density and Relative Density for Chemical Products. Beijing: General Administration of Quality Supervision, Inspection and Quarantine.

Geng, L. T., Xu, Q., Ren, R. B., Wang, L. Z., Yang, X. L., and Wang, X. Y. (2016). Performance research of high-viscosity asphalt mixture as deck-paving materials for steel bridges. Road Mater. Pavement Design 18, 1-13.

Guan, Y. S., Chi, Z. H., and Zong, H. (2005). Analysis and Countermeasure for early disease of long-span steel bridge deck pavement. J. China Foreign Highways 25, 99-101.

Hee, M. P., Ji, Y. C., and Hyun, J. L. (2017). Performance evaluation of a high durability asphalt binder and a high durability asphalt mixture for bridge deck pavements. Construct. Build. Mater. 23, 219-225. doi: 10.1016/j.conbuildmat. 2008.01.001

Hou, Y., Wang, L., Wang, D., Qu, X., and Wu, J. (2017). Using a molecular dynamics simulation to investigate the asphalt nano-cracking under external loading conditions. Appl. Sci. 7:770. doi: 10.3390/app7080770

Ionita, D., Cristea, M., and Gaina, C. (2020). Prediction of polyurethane behaviour via time-temperature superposition: meanings and limitations. Polymer Test. 83:106340. doi: 10.1016/j.polymertesting.2020.106340

JTG E20-2011 (2011). Standard Test Methods of Bitumen and Bituminous Mixtures for Highway Engineering. Beijing: Ministry of Transport of the People's Republic of China.

JTG F40-2004 (2004). Technical Specifications for Construction of Highway Asphalt Pavements. Beijing: Ministry of Transport of the People's Republic of China.

Li, T. S., Lu, G. Y., Wang, D. W., Hong, B., Tan, Y. Q., and Oeser, M. (2019). Key properties of higlrperformance polyurethane bounded pervious mixture. China J. Highway Transp. 32, 162-173.

Lu, G. Y., Liu, P. F., Törzs, T., Wang, D. W., Oeser, M., and Grabe, J. (2020). Numerical analysis for the influence of saturation on the base course of 
permeable pavement with a novel polyurethane binder. Construct. Build. Mater. 240, 1-10.

Lu, G. Y., Liu, P. F., Wang, Y. H., Sabine, F., Wang, D. W., and Oeser, M. (2019a). Development of a sustainable pervious pavement material using recycled ceramic aggregate and bio-based polyurethane binder. J. Clean. Product. 220, 1052-1060. doi: 10.1016/j.jclepro.2019.02.184

Lu, G. Y., Renken, L., Li, T. S., Wang, D. W., and Oeser, M. (2019b). Experimental study on the polyurethane-bound pervious mixtures in the application of permeable pavements. Construct. Build. Mater. 202, 838-850. doi: 10.1016/j. conbuildmat.2019.01.051

Luo, S. G., Zhang, J. G., Tan, H. M., Jing, F. Y., and Chen, F. T. (1999). Thermmooxidative degradation of copolyether-urethan. Chin. J. Appl. Chem. 04, 14-17.

$\mathrm{Ni}$, F. J., and Yin, Y. M. (2005). Fatigue properties of asphalt mixture with fiberglass polyester mat. J. Traff. Transp. Eng. 03, 31-35.

Qian, Z. D., Liu, Y., Liu, C. B., and Zheng, D. (2016). Design and skid resistance evaluation of skeleton-dense epoxy asphalt mixture for steel bridge deck pavement. Construct. Build. Mater. 114, 851-863. doi: 10.1016/j.conbuildmat. 2016.03.210

Shen, G. L., Sun, S. Y., and Chen, Z. L. (2014). Study on aging mechanism and research methods of polyurethane. Aging Appl. Synth. Mater. 43, $57-64$.

Shi, Z. X. (2018). Development and Evaluation of High Performance Materials for Steel Bridge Deck Pavement. Master thesis, Beijing University of Civil Engineering and Architecture, Beijing.

Sun, H. J., and Chen, S. (2014). Study on the influence of materials and structural factors on the durability of asphalt pavement of concrete bridge. J. China Foreign Highway 6, 260-263.

Wang, D., Liu, P., Leng, Z., Leng, C., Lu, G., Buch, M., et al. (2017a). Suitability of PoroElastic road surface (PERS) for urban roads in cold regions: mechanical and functional performance assessment. J. Clean. Product. 165, 1340-1350. doi: 10.1016/j.jclepro.2017.07.228

Wang, D., Schacht, A., Leng, Z., Leng, C., Kollmann, J., and Oeser, M. (2017b). Effects of material composition on mechanical and acoustic performance of poroelastic road surface (PERS). Construct. Build. Mater. 135, 352-360. doi: 10.1016/j.conbuildmat.2016.12.207
Wang, H. M., Li, R. K., Wang, X., Ling, T. Q., and Zhou, G. (2014). Strength and road performance for porous polyurethane mixture. China J. Highway Transp. 27, 24-31.

Wang, R. W., Hu, Z. H., Shi, J. L., Li, S. F., Xu, S. F., and Duan, W. Z. (2018). Development and pavement performance evaluation of paving materials with high molecular polymer. Road Construct. Mach. Construct. Mechan. 35, 39-42.

Wang, Z. Y., and Liu, L. J. (2013). Study on the durability of highway bridge under heavy traffic. Appl. Mechan. Mater. 340, 100-103. doi: 10.4028/www.scientific. net/amm.340.100

Xu, H., Li, H., Tan, Y., Wang, L., and Hou, Y. (2018). A Micro-scale investigation on the behaviors of asphalt mixtures under freeze-thaw cycles using entropy theory and a computerized tomography scanning technique. Entropy 20:68. doi: $10.3390 /$ e20020068

Yang, Q., Hong, B., Lin, J., Wang, D., Zhong, J., and Oeser, M. (2020a). Study on the reinforcement effect and the underlying mechanisms of a bitumen reinforced with recycled glass fiber chips. J. Clean. Product. 251:119768. doi: 10.1016/j. jclepro.2019.119768

Yang, Q., Li, X., Zhang, L., Qian, Y., Qi, Y., Kouhestani, H. S., et al. (2020b). Performance evaluation of bitumen with a homogeneous dispersion of carbon nanotubes. Carbon 158, 465-471. doi: 10.1016/j.carbon.2019.11.013

Yang, W. M. (2013). Study on Diseases for Asphalt Concrete Paved on Bridge. Master thesis, Chang' an University, Xi'an.

Zhang, H. L., Zhang, G. W., Han, F. F., Zhang, Z. P., and Lv, W. J. (2018). A lab study to develop a bridge deck pavement using bisphenol a unsaturated polyester resin modified asphalt mixture. Construct. Build. Mater. 159, 83-98. doi: 10.1016/j.conbuildmat.2017.10.126

Conflict of Interest: The authors declare that the research was conducted in the absence of any commercial or financial relationships that could be construed as a potential conflict of interest.

Copyright (c) $2020 \mathrm{Xu}, \mathrm{Xu}$, Zhang, Guo, Peng and Xu. This is an open-access article distributed under the terms of the Creative Commons Attribution License (CC BY). The use, distribution or reproduction in other forums is permitted, provided the original author(s) and the copyright owner(s) are credited and that the original publication in this journal is cited, in accordance with accepted academic practice. No use, distribution or reproduction is permitted which does not comply with these terms. 